\title{
Kinematic and dynamic analysis and distribution of stress for six-item mechanism
}

\author{
Ján Vavro Jr. ${ }^{1, *}$, Ján Vavro $^{1}$, Petra Kováčiková ${ }^{1}, J a k u b$ Híreš ${ }^{1}$ \\ ${ }^{1}$ Faculty of industrial Technologies in Púchov, Alexander Dubček University of Trenčín, I. Krasku \\ 491/30, 02001 Púchov, Slovak Republic
}

\begin{abstract}
This paper presents a kinematic and dynamic analysis and distribution of the stress for six-item planar mechanism by means of the SolidWorks software. Graphic dependence of kinematic and dynamic magnitudes of some points is given in dependence on the angle of rotation of the driving item and in dependence on the time. Distribution of the stress in the items is presented in [Pa]. In relation to the kinematic and dynamic analysis and subsequent simulation of the planar as well as spatial mechanisms, it is great solution to use SolidWorks software program. The considerable advantage of this mentioned program is based on its simplicity from the aspect of modeling and moreover, it is important to point out that utilisation of the mentioned program leads to results which are precise and accurate in the case of the numerical solution of the equations in the whole magnitude referring to motion of mechanism while the given results are obtained in the graphic form.
\end{abstract}

Keywords: kinematic analysis, dynamic analysis, finite element method, planar mechanism

\section{Kinematic and dynamic analysis of planar mechanism}

The planar mechanism representative (Fig. 1) consists of six bodies and it was used as computational model. Using the kinematic analysis [4-6] and dynamic analysis and subsequent simulation [1-3], the main objective is connected with the determination and entering of the position domains, speed (velocity) domains as well as acceleration of the individual bodies in relation to the specified input values of the angular velocity for the driving body designated as 2 . The angular velocity for the body, designated as 2 , is specified in this way: $\omega_{21}=1[\% / \mathrm{s}]$ and $\alpha_{21}=0.7\left[{ }^{\circ} / \mathrm{s}^{2}\right]$, where $\omega_{21}=1[\% / \mathrm{s}]$ is not constant and it is changed in dependence on time (Fig. 2). Specified input values can be seen in (Fig. 3).

\footnotetext{
* Corresponding author: jan.vavro.jr@,fpt.tnuni.sk

Reviewers: Vladimir Dekýš, Petr Horyl
} 


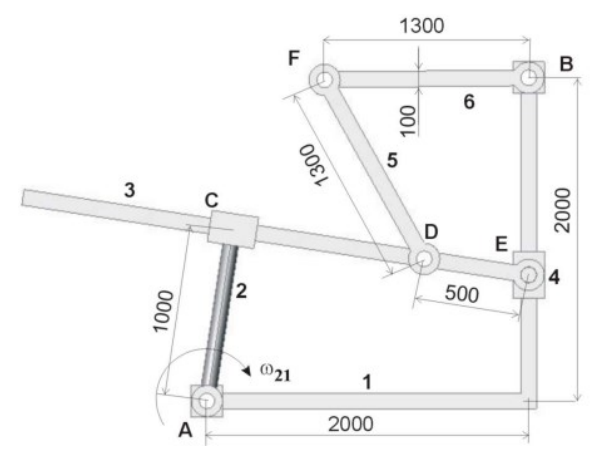

Fig. 1. Planar mechanism - computational model

Course of input value for angular velocity and angular acceleration is in Fig. 2 and Fig. 3.

\section{Angular velocity of 2, 5, 6 bodies in dependence} on time

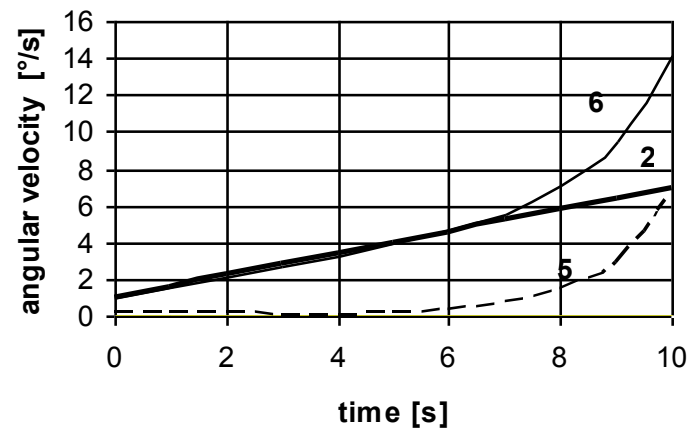

Fig. 2. Angular velocity of 2, 5, 6 bodies in dependence on time

Angular acceleration of 2, 5, 6 bodies in dependence on time

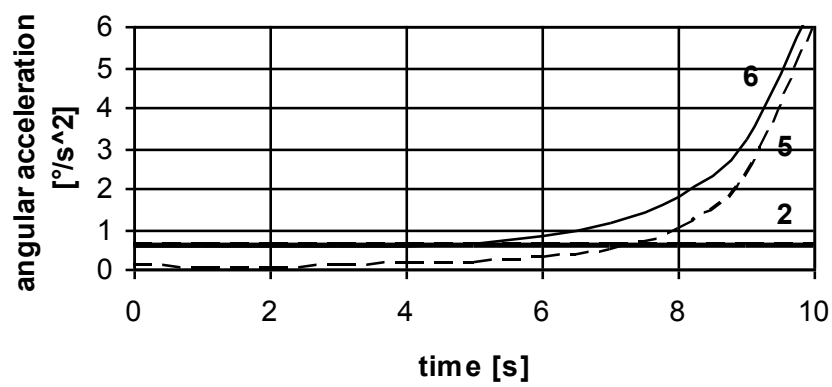

Fig. 3. Angular acceleration of 2, 5, 6 bodies in dependence on time 
The simulation [12] of operation relating to planar mechanism can be seen in the Fig. 4 for time step referring to one second while the whole simulation takes place for ten seconds.
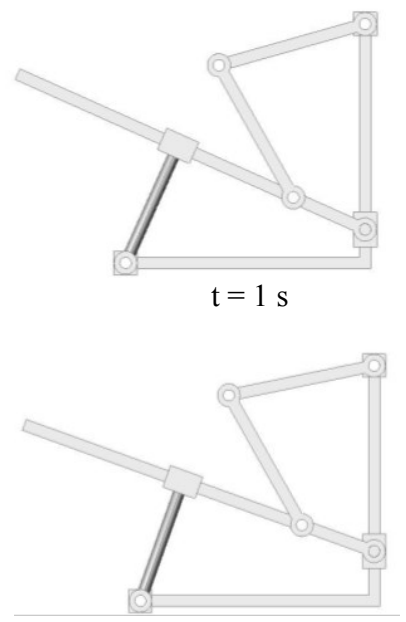

$\mathrm{t}=3 \mathrm{~s}$

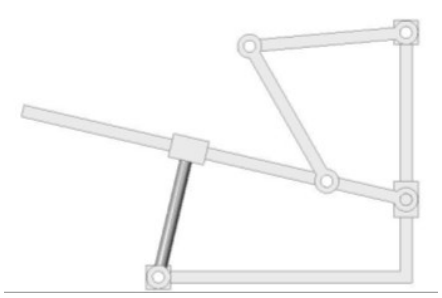

$\mathrm{t}=5 \mathrm{~s}$

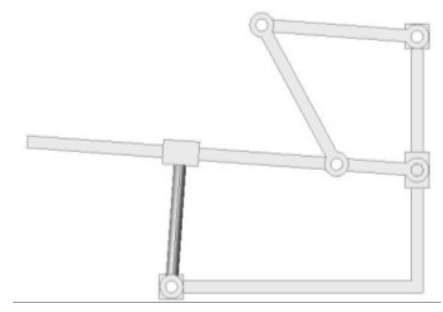

$\mathrm{t}=7 \mathrm{~s}$

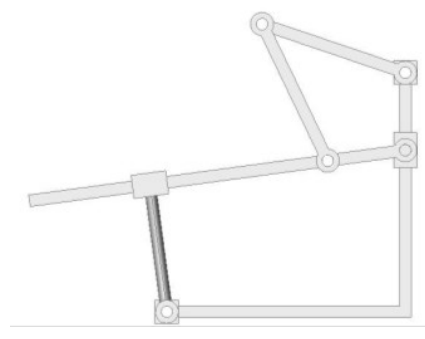

$\mathrm{t}=9 \mathrm{~s}$
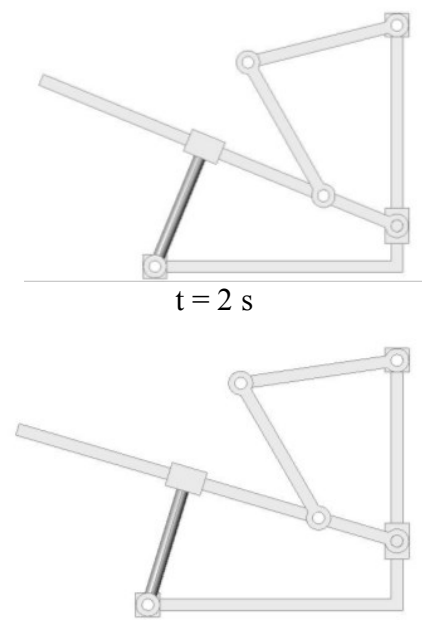

$\mathrm{t}=4 \mathrm{~s}$

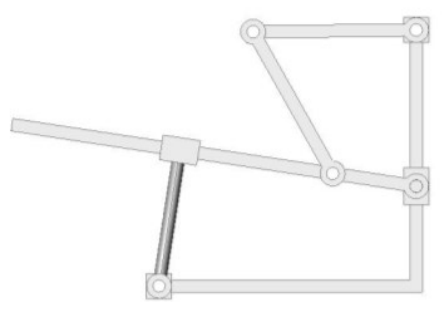

$\mathrm{t}=6 \mathrm{~s}$

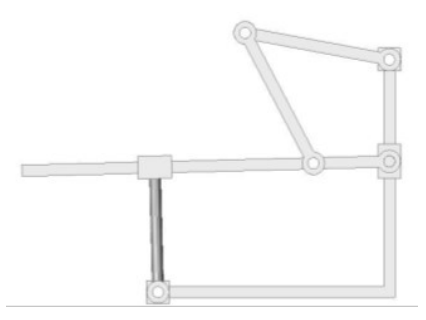

$\mathrm{t}=8 \mathrm{~s}$

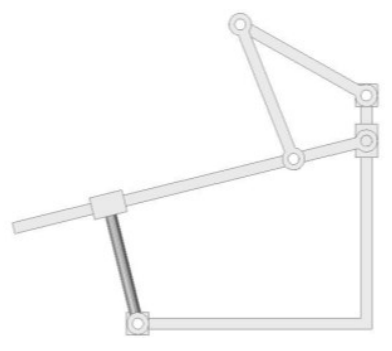

$\mathrm{t}=10 \mathrm{~s}$

Fig. 4. Simulation of planar mechanism operation for ten positions 
The whole course of the velocity and acceleration for C, D, E, F points of bodies can be seen in Fig. 5 and Fig. 6.

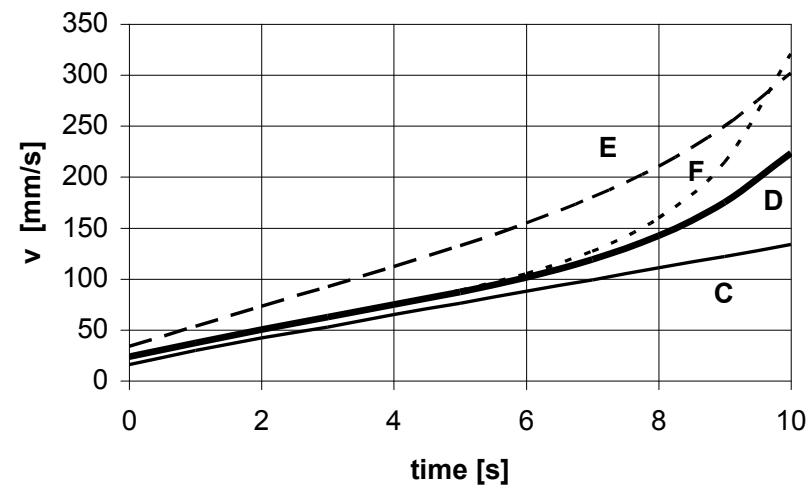

Fig. 5. Velocity in points (C, D, E, F) - dependent on the time

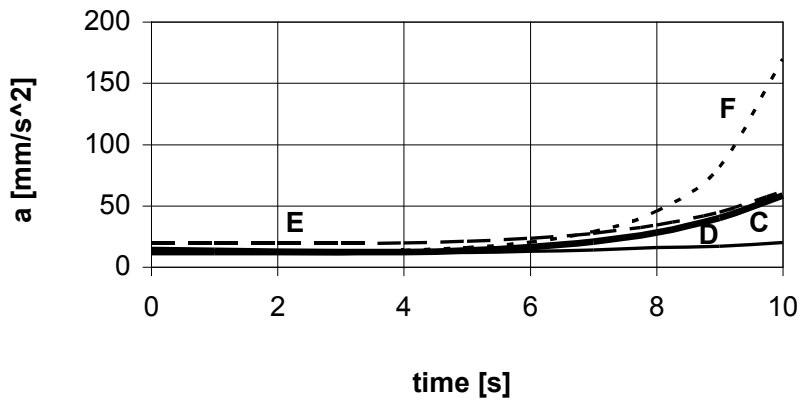

Fig. 6. Acceleration in points (C, D, E, F) - dependent on the time

The main objective of the dynamic analysis is connected with specification of the loading for the individual items and determination of the courses relating to mutual reactions, referring to individual kinematic connections [7], [10-11]. The analysis was based on utilisation of the linear model. Relating to the analysis, the other important values were utilised:

- modulus of elasticity (Young's modulus): $\mathrm{E}=2.1 \mathrm{e}^{11}[\mathrm{~Pa}]$,

- Poisson's ratio: $\mu=0.3$,

- density of material: $\rho=7850\left[\mathrm{~kg} \cdot \mathrm{m}^{-3}\right]$.

Fig. 7 represents the course of the reaction in F point of the body, designated as 6 and Fig. 8 represents the course of the reaction in $\mathrm{D}$ point of the body, designated as 5 . 


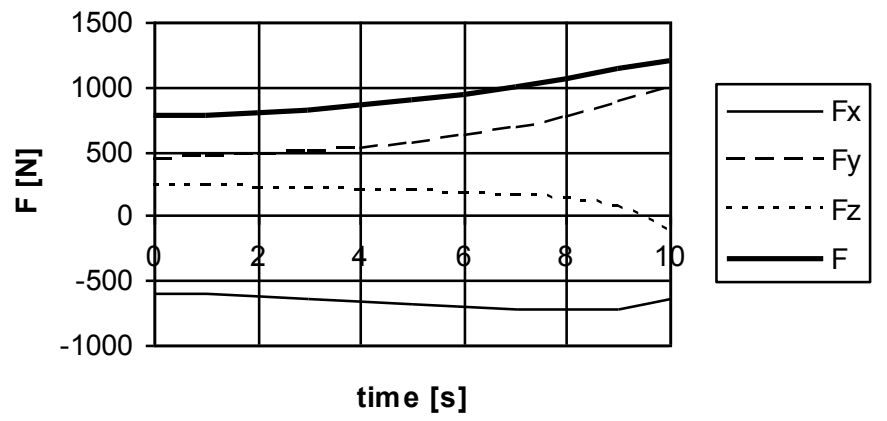

Fig. 7. Course of the reaction in F point of the body, designated as 6 - dependent on the time

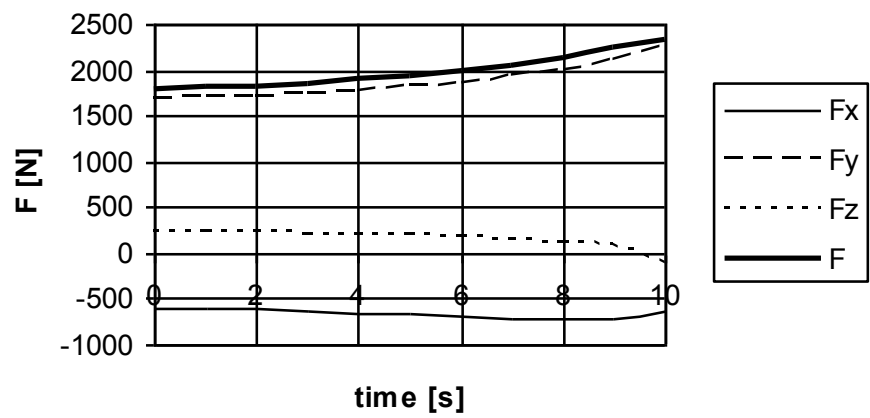

Fig. 8. Course of the reaction in D point of the body, designated as 5 - dependent on the time

\section{Distribution of the Stress in Items of Planar Mechanism}

The distribution of the stress for linked bodies [8-9], designated as 1, 2, 3, 5 can be seen in Figs. 9-16.

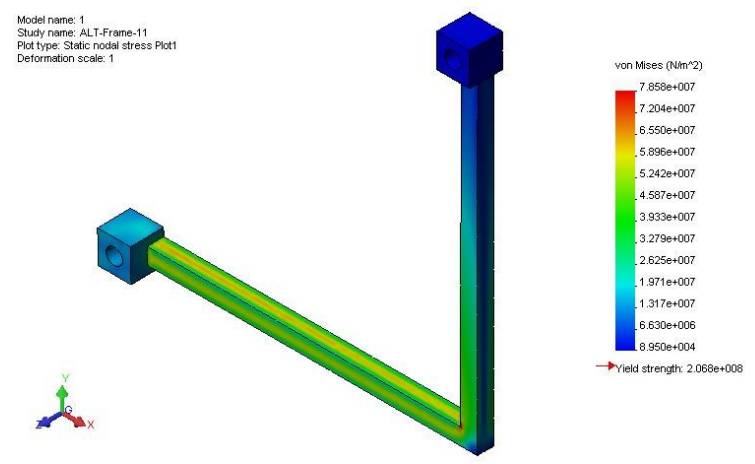

Fig. 9 Distribution of the stress for body designated as 1 in $[\mathrm{Pa}]$ 


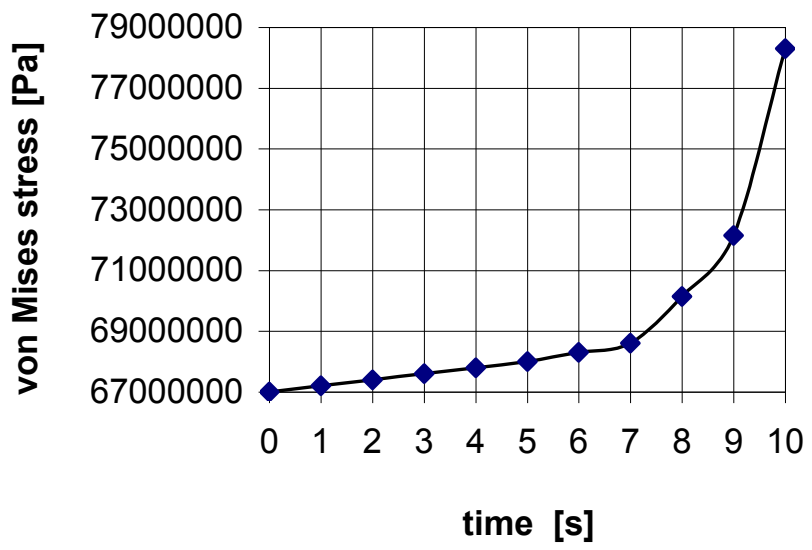

Fig. 10 Course of the stress for body, designated as 1 - dependent on the time
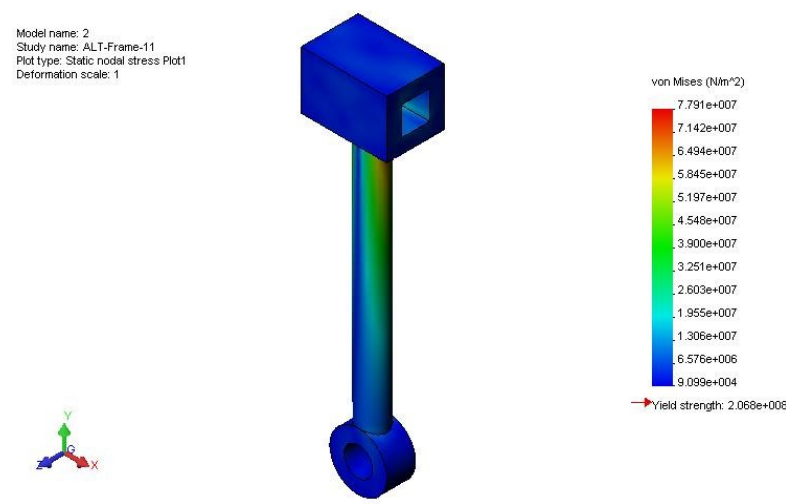

Fig. 11 Distribution of the stress for body, designated as 2 in [Pa]

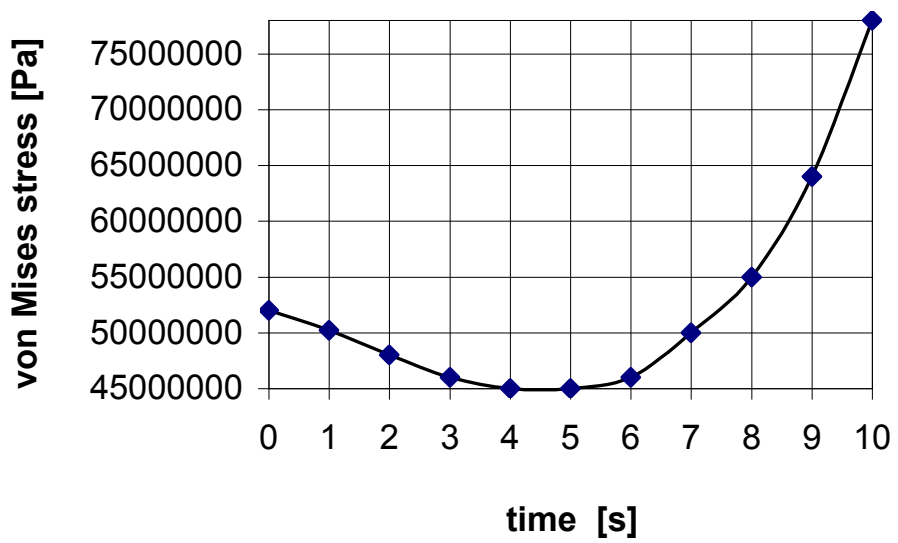

Fig. 12. Course of the stress for body, designated as 2 - dependent on the time 


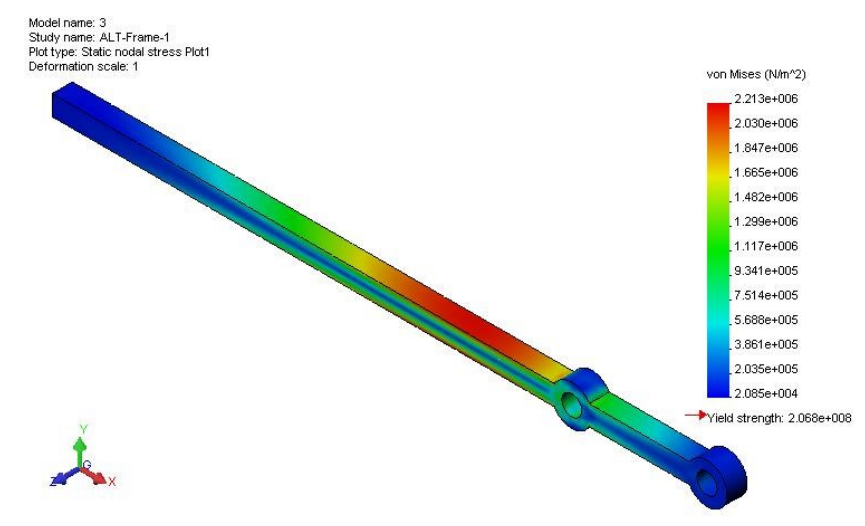

Fig. 13. Distribution of the stress for body, designated as 3 in $[\mathrm{Pa}]$

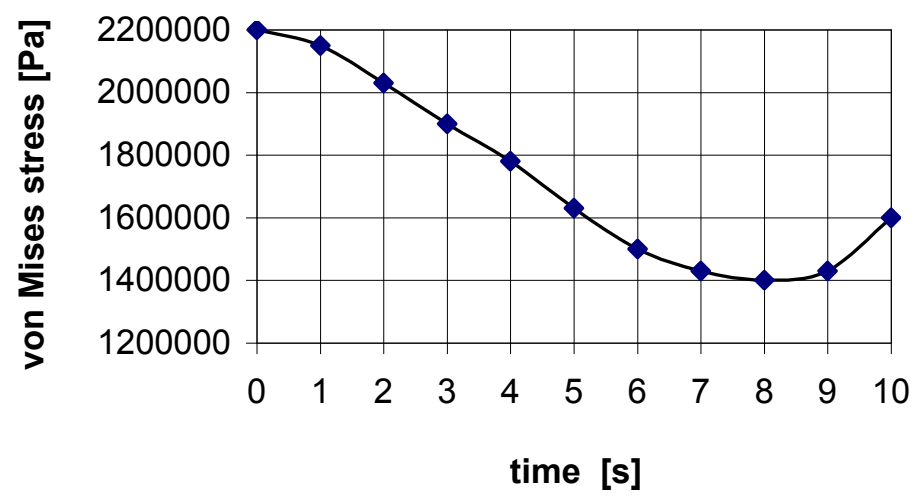

Fig. 14. Distribution of the stress for body, designated as 3 in $[\mathrm{Pa}]$

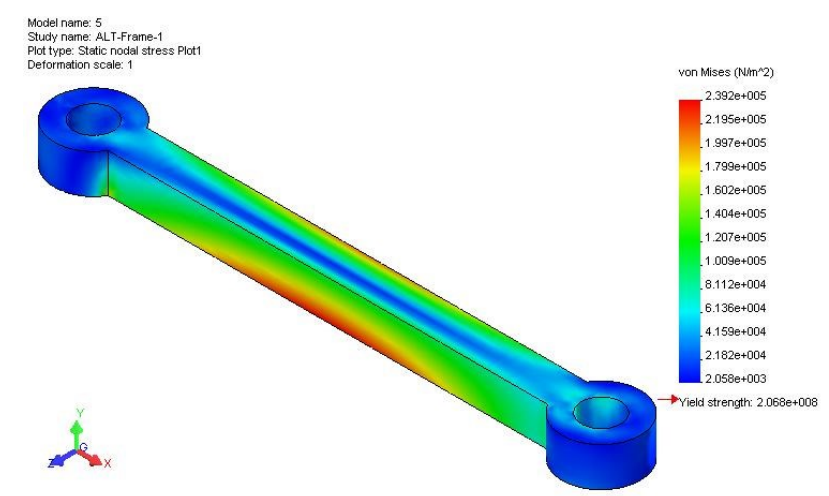

Fig. 15. Course of the stress for body, designated as 5 - dependent on the time 


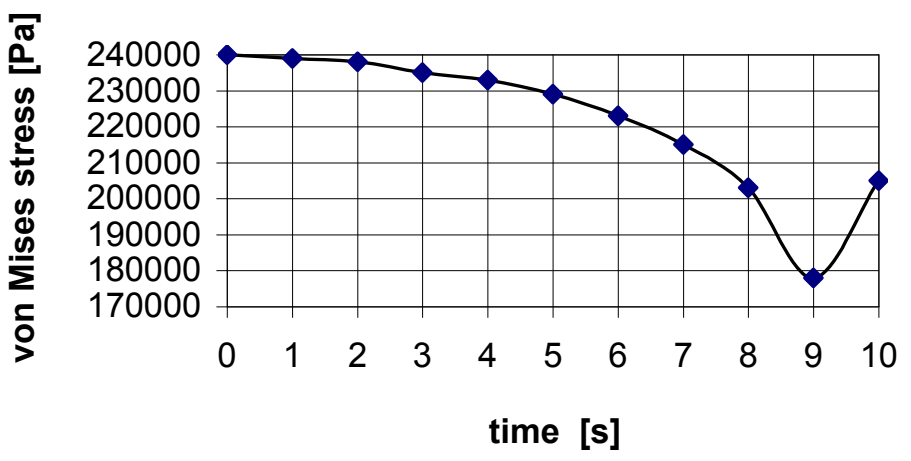

Fig. 16. Course of the stress for body, designated as 4 - dependent on the time

\section{Conclusion}

Based on the evaluation of the results, the utilisation of the Motion Program is significantly useful because it is effective way to determine all kinematic parameters of any mechanism and moreover, the loading for any point of the body system is able to be specified. The tolerance for the position deviation was also tested while the predetermined deviation was $10^{-9}$. It is important to point out that from the aspect of convergence, it was not necessary to use more than five steps for each one position. On the other side, the convergence failure was connected with specification and entering of inaccurate parameters.

This work was supported by the Slovak Grant Agency VEGA 1/0649/17, VEGA 1/0589/17, KEGA 007TnUAD-4/2017, and resulted from the project "Center for quality testing and diagnostics of materials", ITMS code 26210120046 relating to the Operational Program Research and Development funded from European Fund of Regional Development.

\section{References}

1. B. Paul, Kinematics and Dynamics of Planar Machinery. (Prentice-Hall, New Jersey, 1979)

2. V. Brát, Handbook of kinematics with examples. (SNTL, Prague, 1976)

3. A. Sapietová, M. Saga, B. Hyben, M. Sapieta, Effective methods of parameters refinement of machinery in the program MSC ADAMS, Applied Mechanics and Materials 611, 67-74 (2014)

4. A. Sapietová, M. Sapieta, B. Hyben, Document Sensitivity analysis application for multibody system synthesis. Applied Mechanics and Materials 420, 68-73 (2013)

5. M. Sága, M. Vaško, P. Pecháč, Chosen numerical algorithms for interval finite element analysis. Procedia Engineering 96, 400-409 (2014)

6. A. Sapietová, V. Dekýš, M. Vaško, A numerical model of rotating machine having unbalance and the measurements of its dynamical properties. Metalurgija (Metalurgy) 49, 503-507 (2010)

7. A. Sapietová, M. Sága, P. Novák, R. Bednár, J. Dižo, Design and application of multisoftware platform for solving of mechanical multi-body system problems. Mechatronics: Recent technological and scientific advances, 345-354 (2011) 
8. F. Klimenda, J. Soukup, M. Zmindak, Deformation of Aluminium Thin Plate. Manufacturing Technology 16, ISSN 1213-2489, 124-129 (2016)

9. A. Sapietová, V. Dekýš, M. Sapieta, P. Pecháč, Application of computational and design approaches to improve carrier stability. Procedia Engineering 96, 410-418 (2014)

10. M. Handrik, P. Kopas, V. Baniari, M. Vaško, M. Sága, Analysis of stress and strain of fatigue specimens localised in the cross-sectional area of the gauge section testing on bi-axial fatigue machine loaded in the high-cycle fatigue region. Procedia Engineering 177, 516-519 (2017)

11. J. Zapoměl, V. Dekýš, P. Ferfecki, A. Sapietová, M. Sága, M. Žmindák, Identification of material damping of a carbon composite bar and study of its effect on attenuation of its transient lateral vibrations. Int. Journal of Applied Mechanics 7 (6), (2015)

12. I. Delyová, D. Hroncová, P. Frankovský, Analysis of Simple Mechanism Using MSC Adams. Manufacturing Technology 14, ISSN 1213-2489, 141-145 (2014) 